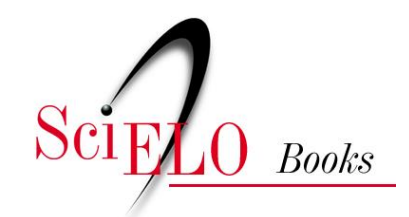

\title{
Desenvolvimento e turismo
}

para além do paradigma econômico

\author{
Maria Dilma Simões Brasileiro
}

\section{SciELO Books / SciELO Livros / SciELO Libros}

BRASILEIRO, MDS. Desenvolvimento e turismo: para além do paradigma econômico. In BRASILEIRO, MDS., MEDINA, JCC., and CORIOLANO, LN., orgs. Turismo, cultura e desenvolvimento [online]. Campina Grande: EDUEPB, 2012. pp. 75-98. ISBN 978-85-7879-194-0. Available from SciELO Books < http://books.scielo.org>.

\section{(c) (1) @()}

All the contents of this work, except where otherwise noted, is licensed under a Creative Commons Attribution-Non Commercial-ShareAlike 3.0 Unported.

Todo o conteúdo deste trabalho, exceto quando houver ressalva, é publicado sob a licença Creative Commons Atribuição Uso Não Comercial - Partilha nos Mesmos Termos 3.0 Não adaptada.

Todo el contenido de esta obra, excepto donde se indique lo contrario, está bajo licencia de la licencia Creative Commons Reconocimento-NoComercial-CompartirIgual 3.0 Unported. 


\title{
Desenvolvimento e turismo: para além do paradigma econômico
}

\author{
Maria Dilma Simões Brasileiro
}

\section{Introdução}

O turismo vem adquirindo um lugar relevante nas reflexões e produções científicas. A sociologia, geografia, administração, economia, comunicação, dentre outras áreas, têm se preocupado com as questões relacionadas ao turismo e seus impactos nas localidades, regiões e países. Assim mesmo, o turismo tem assumido centralidade nas agendas contemporâneas, não somente no âmbito acadêmico, mas também no âmbito governamental e empresarial.

A ênfase desta centralidade do turismo tem recaído predominantemente no paradigma econômico, principalmente quando se trata das agendas dos governos locais, regionais ou nacional. As transversalidades que perpassam as complexas relações ambientais, socioculturais, econômicas e políticas 
que se constroem e se reconstroem nos destinos turísticos não estão sendo acompanhadas, na maioria dos casos, por uma análise e reflexão mais crítica. Por outro lado, as produções acadêmicas da área do turismo, dentre os diversos paradigmas e interpretações teóricas dos autores, têm dedicado uma maior atenção à observação empírica. Estes estudos não têm avançado na vinculação dos fatos observados com um quadro de referência teórico-conceitual que permita a elaboração mais profunda de um arcabouço interpretativo deste fenômeno social moderno.

Os discursos acadêmicos se constroem por meio de um conjunto complexo de análise da realidade, que vai alimentar e ser retroalimentado pelas realidades as quais interpreta. Como afirma Zaoual (2003, p.19), "as ideias conduzem o mundo”. É neste contexto que as reflexões teórico/conceituais sobre o turismo contribuem e se constituem uma análise importante da realidade contemporânea, principalmente quando associadas ao contexto do desenvolvimento.

Este ensaio tem por objetivo abordar outras perspectivas, para além da econômica, nas discussões sobre o desenvolvimento e o turismo. A abordagem aqui empregada, baseada em pressupostos do desenvolvimento sustentável e suas variantes, reconhece que o crescimento econômico é uma condição necessária, mas não suficiente, para promover a qualidade de vida dos cidadãos, principalmente quando se faz referência aos países periféricos. $\mathrm{O}$ turismo por sua vez, é analisado como uma possibilidade de realização dos novos modelos e paradigmas de desenvolvimento local sustentável. Turistas e autóctones são aqui entendidos como atores, sujeitos ativos deste complexo fenômeno sociocultural. 


\section{A construção do Desenvolvimento}

O conceito de desenvolvimento está associado à modernidade. Os valores burgueses do individualismo, da racionalidade, do trabalho, da ordem, do progresso e da acumulação de capital se transformam em valores supremos das sociedades ocidentais. A acumulação de capital se constrói pelo excedente e o desenvolvimento é uma das formas que assumem esse excedente (FURTADO, 1984). Neste sentido, os fundamentos do capitalismo, com os ideais de riqueza e progresso, sentam suas bases na revolução industrial, como único modelo possível para o desenvolvimento dos Estados-nação modernos.

O Estado moderno, racional e centralizado, assegurando o controle e a disciplina social, coabita com o capitalismo. $\mathrm{O}$ crescimento econômico passa a ser o índice de modernização e, nesta perspectiva, quanto mais industrializados, mais desenvolvidos são os Estados-nação. Disciplina, autocontrole e adaptabilidade dos indivíduos são exigidos para o progresso capitalista. São valores modernos que, associados ao trabalho, constroem a base para o progresso nacional. Desde esta perspectiva, o progresso é constituído por estágio de crescimento em linha ascendente, em que o estágio anterior é a base para o estágio posterior.

Por seu turno, com a ascensão da burguesia, o eurocentrismo se generaliza como princípio fundamental entre os diversos povos do mundo. Os Estados-nação que não participam dos valores e realidades europeias são considerados extraordinários e estão aquém no estágio de progresso necessário para o seu crescimento. Para esses Estados-nação, o processo 
de socialização europeia é necessário para a interiorização dos valores burgueses. Este processo permitirá uma adaptação e reprodução de Estado, cultura e mercado moderno nesses países colonizados.

No caso do Brasil, o processo de europeização, no sentido de individualismo moral e capitalista, chega tardiamente, em 1808, com a abertura dos portos e a vinda da família real portuguesa (JESSÉ DE SOUZA, 2002). Como analisa este autor, este processo se dá de fora para dentro, a partir da extraordinária eficácia das instituições do Estado e do mercado. Estas duas instituições transformam toda hierarquia social e os valores fundamentais da sociedade brasileira.

Destaca-se que esta transformação é seletiva, não abrangendo, como exemplifica Jésse de Souza (2002), os descendentes de escravos e dependentes rurais de todas as etnias. A tese defendida por este autor é a de que a desigualdade, o atraso social e democrático de sociedades modernas e periféricas como o Brasil, e vários outros países periféricos de situação histórica semelhante, não são um resíduo pré-moderno que se mantém nessas sociedades, mas é o resultante de um efetivo processo de modernização de grandes proporções que aconteceu no Brasil no início do século XIX. O argumento utilizado por Jessé de Souza para esta tese sobre o desenvolvimento nos países periféricos, ou a falta dele, é que a desigualdade, e sua naturalização na vida cotidiana, é moderna, e está vinculada à eficácia dos valores e instituições europeias, a partir de sua bem sucedida importação de "fora para dentro".

Analisando também o processo de modernização e das desigualdades sociais dos países da América Latina, África e Ásia desde a independência, Rivero (2002) ressalta que a 
maioria dos Estados-nação nascidos no século XIX, e quase todos do século XX, apresentam projetos nacionais incompletos que não se desenvolveram, isto é, são Quase-Estadosnação. $\mathrm{Na}$ análise deste autor, embora a independência desses países tenha devolvido a dignidade a povos dominados e discriminados, o modelo do Estado-nação europeu, em comunidades desprovidas do conceito de Estado e instituições, sem burguesia e mercado nacional tornou inviável o processo de descolonização.

Os processos históricos e sociais vividos pelo mundo depois da Segunda Guerra Mundial também não foram suficientes para provocar mudanças estruturais nesses QuaseEstados-nação. Neste período, foram criadas as grandes instituições internacionais, tais como o Banco Mundial, a Organização das Nações Unidas (ONU), o Fundo Monetário Internacional (FMI), dentre outras, promovendo, por consequência, a institucionalização do desenvolvimento. A pauta dominante era um Estado desenvolvimentista ativo com prioridade para o pleno emprego, a importância do Estado de bem-estar, a necessidade de planejamento e a intervenção do Estado nos assuntos econômicos (SACHS, 2008).

No pós-guerra, os países centrais também elaboraram várias intervenções para reduzir as diferenças entre esses países e os periféricos. Não com o objetivo de reduzir as dívidas históricas com os países periféricos, mas para a sobrevivência do próprio sistema econômico capitalista. Associada à intervenção dessas instituições internacionais, instala-se a crença de que o progresso dos países centrais poderá ser implementado nos países periféricos, desde que haja vontade política, com esforços sistemáticos de ordem social e econômica, segundo critérios adotados pelos países centrais. 
A nova organização mundial na segunda metade do século XX produz também um novo tipo de dependência dos países periféricos da África, alguns da Ásia e da América Latina. Os dois blocos rivais criados com a Guerra Fria, após o fim da Segunda Guerra Mundial, introduziram mecanismos de ajuda internacional para os Estados-nação periféricos. Entretanto, o objetivo primeiro dessa intervenção internacional foi o de garantir influência estratégica nessas nações, na disputa entre a ex-União Soviética e os Estados Unidos, promovendo assim um novo tipo de colonialismo.

Nesta nova ordem mundial, o crescimento econômico torna-se cada vez mais o grande objetivo dos Estados-nação, estando os demais aspectos da vida social, política, cultural e ambiental subordinados a eles. Nesse período do pósguerra, os países considerados desenvolvidos experimentam uma fase de crescimento e expansão econômica e tecnológica sem precedentes - a idade de ouro - apresentado nas décadas de 50 e 60 o crescimento mais rápido da história (ANDERSON, 2008).

O Brasil, por sua vez, também acompanha este crescimento econômico, com um crescimento industrial bastante acelerado. Entretanto, a situação econômica da maior parte dos cidadãos brasileiros pouco, ou quase nada, beneficiou-se deste crescimento econômico. Outros países também considerados periféricos, na própria América Latina, apresentaram pequeno desenvolvimento, para depois entrarem numa fase de estancamento, inclusive em retrocesso, vivendo uma explosão de necessidades, tais como de alimentação, saúde, educação, moradia, dentre outras. 
Com o fim da Guerra Fria, termina também o valor estratégico desses países, sendo os mesmos abandonados a sua autodeterminação, sem, entretanto, possuírem condições mínimas de governabilidade, de viabilidade econômica e sem capacidade de promover qualidade de vida a sua população. Como argumenta Rivero (2002), devido às condições sociopolíticas, econômicas e culturais, as experiências vividas pelas ex-colônias britânicas, como os Estados Unidos, o Canadá, a Austrália ou Nova Zelândia, que alcançaram altos níveis de vida para a população, dificilmente serão repetidas pelos novos Estados-nação. Veiga (2005), analisando também o processo de colonização conduzido pela Inglaterra e pelos países da Península Ibérica, afirma que estes últimos não tinham maturidade capaz de alicerçar o crescimento econômico, com bases modernas, nessas novas colônias. Entretanto, EUA e Canadá tiveram como fonte as próprias instituições britânicas, propulsoras da industrialização e do Estado moderno.

Esta realidade vivida pelos países considerados periféricos é analisada pelos países centrais como uma fase do próprio processo de desenvolvimento. Seguindo o modelo adotado pelos países centrais, os países periféricos chegarão ao atual estágio vivido por eles, não só na dimensão econômica e técnico-científica, mas também na dimensão moral, social e política. Esta perspectiva de desenvolvimento está associada à ideia de progresso, e o problema reside em: "Como garantir a continuidade em direções determinadas, se o universo é pleno de surpresas, num mundo descontínuo formado de sobressaltos?" (DUPAS, 2006, p. 31)

Como se sabe, esta perspectiva linear do progresso, associada ao crescimento econômico, não corresponde à realidade 
vivida pelos Estados-nação periféricos. Assim mesmo, a linearidade do progresso tampouco é experimentada pelos países centrais. A grande crise em 1973, por exemplo, lança o mundo capitalista numa longa e profunda recessão, que muda a relação do Estado com as economias de mercado. Nos anos 80, virá o triunfo da ideologia neoliberal nos Estados Unidos e em quase todos os países da Europa ocidental, colocando em prática o programa neoliberal (ANDERSON, 2008, p. 12). Porém, como analisa Sachs (2008), o evangelho neoliberal dominou a cena até o final dos anos 90, pois este modelo também não foi capaz de cumprir com suas promessas, nem mesmo para os países desenvolvidos.

Os próprios países periféricos, por outro lado, buscam compreender e explicar as causas dessas assimetrias econômicas e sociais, ao invés de aceitá-las de forma linear e evolutivamente. $\mathrm{O}$ modelo de crescimento concentrador e excludente é assim analisado pelos intelectuais dos países periféricos que colocam, em xeque, este modelo adotado pelos países centrais. O progresso, "perseguido e idolatrado pelo ocidente, traz consigo também a exclusão, a concentração de renda e o subdesenvolvimento" (DUPAS, 2006, p.11), ou seja, o próprio modelo de crescimento econômico adotado pelos países centrais é o gerador das relações assimétricas entre os Estadosnação modernos.

As análises com base exclusiva no crescimento econômico e no progresso técnico/científico não permitem revelar o processo multidimensional do desenvolvimento. O progresso econômico e técnico/científico é ambivalente e nem sempre significa qualidade de vida e desenvolvimento para a população. Principalmente quando o crescimento econômico 
torna-se um fim em si mesmo, a partir de critérios e índices exógenos. Como ressalta Furtado (1984), o desenvolvimento se realiza quando os valores humanos se abrem para a capacidade criativa e a acumulação se difunde em segmentos importantes da coletividade.

O conceito de desenvolvimento abre-se assim para novos paradigmas, que vão privilegiar novas perspectivas econômicas e introduzir novas problemáticas, como a da sustentabilidade, liberdade individual, diversidade cultural e participação social. Novas configurações e contornos do conceito de desenvolvimento vão provocar mudanças na política, na economia, nos comportamentos humanos e nas organizações institucionais.

\section{Novas possibilidades de Desenvolvimento}

Desde a perspectiva de outras possibilidades e modelos de desenvolvimento, as questões humanas e ambientais ganham centralidade. Novos modelos são criados e recriados, com o intuito de apresentar outros caminhos e propostas alternativas para promover a inclusão social, a valorização de bens culturais e ambientais, e o bem-estar econômico. A partir dessas novas leituras, a produção e a prosperidade econômica, que eram vistas como a essência do progresso, tornam-se meio para o desenvolvimento dos valores humanos.

Sachs (2008) comunga com as proposições do Desenvolvimento Sustentável, como alternativa ao desenvolvimento da boa sociedade, com meios de existência viáveis e trabalho decente. Para este autor, a boa sociedade é aquela 
que maximiza as potencialidades, talentos e imaginação de cada ser humano, na busca de autorrealização e felicidade, por meio de empreendimentos individuais e coletivos, numa combinação de trabalho autônomo e heterônomo e de tempo dedicado a atividades não produtivas, ou seja, com disponibilidade para o tempo livre.

Desde a perspectiva de Sachs (2008), os aspectos qualitativos são essenciais para o desenvolvimento sustentável. As formas de produção não podem se apoiar em esforços excessivos, extenuantes, mal pagos e realizados em condições insalubres dos seus produtores. O direito ao trabalho é visto pelo seu duplo valor, ou seja, intrínseco e instrumental, já que o trabalho decente, como defende Sachs, abre caminho para o exercício de vários outros direitos. Para que haja desenvolvimento sustentável é necessário que se promova, portanto, o crescimento econômico com impactos positivos nos âmbitos sociais e ambientais, sendo a sustentabilidade social um componente essencial deste conceito.

A sustentabilidade social está essencialmente relacionada ao Desenvolvimento Includente (SACHS, 2008). Este conceito faz oposição ao desenvolvimento do mercado de consumo e concentrador de renda e riqueza. Desde esta perspectiva, a educação é essencial para o desenvolvimento, pelo seu valor intrínseco. A educação contribui para o despertar cultural, a conscientização dos direitos humanos, o sentido de autonomia e autoestima. No sentido instrumental, a educação é condição necessária, mas não suficiente, para a empregabilidade. Sachs ainda ressalta que as pessoas necessitam aprender a apreciar, como uma verdadeira medida de sua liberdade cultural, o tempo livre, para a realização de atividades autônomas, em vez de usá-lo para os prazeres do consumo. 
O desenvolvimento também é analisado por Amartya Sen (2000), que considera que a privação de liberdades é um dos maiores problemas da contemporaneidade. Para este autor, a qualidade de vida das pessoas e populações não pode ser medida pelas riquezas materiais, mas pela liberdade. $\mathrm{O}$ crescimento econômico é importante, mas como meio para expandir as liberdades humanas. Sem negar todas as conquistas humanas conseguidas pelo projeto da modernidade, tais como o regime democrático como modelo de organização política; os conceitos de direitos humanos e liberdade política; esperança de vida das pessoas, dentre outros, Sen não deixa de criticar a privação, destituição e opressão vividas por um grande número de pessoas, tanto em países centrais como nos periféricos.

Na discussão sobre a importância da expansão das liberdades individuais para o desenvolvimento, Sen analisa que estas liberdades estão em complementaridade com as disposições sociais, ou seja, em palavras do autor, "é importante o reconhecimento simultâneo da centralidade da liberdade individual e da força das influências sociais sobre o grau e o alcance da liberdade individual" (SEN, 2000, p. 10). O processo de expansão das liberdades reais, desde esta perspectiva, é o principal objetivo do desenvolvimento, que significa remover as principais fontes de privação, como a pobreza, tirania, negligência dos serviços públicos, carência de oportunidades econômicas, manutenção da paz e ordem local, dentre outras. Portanto, liberdade como desenvolvimento é a eliminação de privaçóes de escolhas e a conquista de oportunidades sociais e individuais, para que as pessoas possam exercer sua condição de agente. 
Sen ressalta ainda a necessidade de uma análise integrada das atividades econômicas, sociais e políticas, envolvendo diferentes instituições e agentes de forma interativa. As liberdades instrumentais, incluindo as oportunidades econômicas, liberdades políticas, facilidades sociais, garantias de transparência e segurança protetora, contribuem para a expansão e a garantia das liberdades substantivas dos indivíduos. Neste sentido, os indivíduos são vistos como agentes ativos de mudança e não receptores passivos de benefícios das instituições sociais. A liberdade é, portanto, um determinante de iniciativa individual e da eficácia social.

Desde a perspectiva destes autores, o crescimento econômico apresenta-se como importante, mas não suficiente para determinar o nível de desenvolvimento de uma população. A dimensão cultural, embora considerada, é pouco analisada pelos autores do desenvolvimento. Entretanto, aqui se trabalha com o pressuposto de que a cultura é uma das principais dimensões geradoras de diferenças no desenvolvimento. As condições de bases materiais, objetivas, não são suficientes para explicar o processo de desenvolvimento de uma nação, de um lugar. As explicações para o desenvolvimento nos países centrais e periféricos são também de ordem subjetiva. Desde este ponto de vista, as instituiçôes provedoras do desenvolvimento são resultantes não só de estruturas políticas e econômicas reais, mas são também o resultado dos valores culturais. Estas relações são concretizadas no cotidiano, por meio das interconexões do universo social e cultural dos indivíduos.

Esta abordagem de desenvolvimento, com ênfase nos valores culturais, tem como base a Teoria dos Sítios Simbólicos de Pertencimento (ZAOUAL, 2003). Para este autor, o 
problema dos países periféricos reside na ocidentalização do mundo, imposta pelos países do Norte aos países do Sul, sem considerar a diversidade cultural, religiosa e civilizacional destes países. Assim mesmo, Zaoual analisa que o paradigma econômico da civilização global, abstrato, dedutivo e dividido em especializações estanques, tem conduzido a humanidade em direção a desastres sociais e ambientais. Neste contexto, no esforço de reproduzir os modelos ditados pelo crescimento econômico, o homem ocidentalizado perde de vista a essência humana e sua complexidade.

Paradoxalmente, o processo de globalização, com base no paradigma econômico, tem ampliado o processo de sentimento do local. Nesta tensão entre o global e o local, o autor aponta para o fim do sistema econômico contemporâneo e da exclusividade de sua cultura, e o início de um "pensamento relacional”, antes de racional, associado à ética e à técnica. Como afirma Zaoual (2003, p.21) "as pessoas sentem necessidade de crer e de se inserir em locais de pertencimento”. Desde esta perspectiva, o ser humano sente necessidade de um sítio, espaço em que ele se ancore e se realize como pessoa. Existe no ser humano a necessidade de ser, crer e pertencer a algo. $\mathrm{O}$ sítio é o espaço simbólico, com suas crenças, práticas e significados para a realização da existência humana.

Com base no pensamento da complexidade de Edgar Morin, nos processos de enraizamento de Karl Polanyi e nas ideias de desenvolvimento de Amartya Zen, Zaoual define o sítio simbólico de pertencimento como singular, plural, dinâmico, flexível, complexo e aberto. Desde estas bases, para Zaoaul (2010), o sítio e o Homo situs são relutantes a qualquer reducionismo, seja ele econômico, social ou cultural, 
pois os mundos são complexos e em movimento, gerando diversidade na unidade.

Nenhuma dimensão da existência humana está desarticulada da outra, podendo o conceito de sítio ser aplicado em múltiplas escalas e organizações, em que uma pluralidade de microssítios podem se combinar de diversas maneiras gerando macrossítios. É o ser humano comunicando-se com o seu meio, em que "crenças, conceitos e comportamentos se articulam em torno de um sentido de pertencimento (...)" (ZAOUAL, 2003, p. 29). Os percursos individuais estão entremeados pelos percursos coletivos, reconfigurando continuamente o local. É no espaço vivido que o ser humano torna-se homem vivido concreto, "cujo comportamento enraíza-se em um território, em que harmonia pressupõe a consolidação da multiplicidade do comportamento humano" (Zaoual, 2010, 24). É neste contexto dos novos paradigmas do desenvolvimento, que se analisará o turismo.

\section{Os valores culturais no Turismo}

A teoria dos Sítios Simbólicos de Pertencimento analisa empiricamente o turismo a partir de uma leitura em que certo número de valores imateriais é transformado em valores econômicos (Zaoual, 2008). As análises desta teoria partem da constatação de que o turismo de massa apresenta-se em declínio em algumas partes do mundo, ao mesmo tempo em que emergem outras formas de turismo. Estas outras formas estão associadas à natureza, à cultura e à economia, em uma diversidade e multiplicidade de pertencimento. 
Analisando a trajetória mais recente do turismo, desde os anos 60 até meados dos 80 , o turismo de massa foi a melhor maneira de fazer turismo. Este tipo de turismo é caracterizado por oferecer serviços e produtos homogeneizados, para uma demanda turística inexperiente e motivada basicamente pela oferta de sol e praia, a preços muito baixos, sem maiores preocupações com as questóes ambientais e culturais (BRASILEIRO, 2004). Por outro lado, a oferta do turismo de massa está vinculada a grandes empresas e operadoras do turismo, sendo o êxito de um destino medido pelo lucro imediato e a grande escala. No turismo de massa, os destinos turísticos travam uma grande concorrência entre si, destruindo, na maioria das vezes, os valores socioculturais e ambientais do lugar, em detrimento dos ganhos econômicos.

As paisagens e a cultura do lugar se transformam em produto turístico. Na maioria dos casos, os recursos naturais e as baixas garantias trabalhistas e sociais dos autóctones não são respeitados, principalmente quando os destinos do turismo de massa estão nos países em desenvolvimento e subdesenvolvidos. As desigualdades socioculturais e econômicas são acentuadas entre os autóctones e os turistas, existindo também uma real desarticulação entre as empresas turísticas, as instituições públicas e as pessoas do lugar. $\mathrm{O}$ pensado em escala global pelas multinacionais do turismo e, na maioria das vezes, o planejado pelos governos, não são de conhecimento dos autóctones. Tal qual o processo da modernidade iniciado no século XIX, nos países periféricos, o turismo de massa surge nesses países e lugares como uma imposição ou uma importação dos países centrais, ou seja, como um fenômeno não autóctone, não do lugar. 
Tampouco é experimentado pelos autóctones os tão almejados emprego e renda, divulgados como o grande triunfo do turismo de massa nos lugares. $\mathrm{O}$ argumento utilizado pelos produtores e planejadores do turismo é da falta de qualificação profissional dos autóctones. Esta falta de qualificação não é compatível com o duro mercado competitivo do turismo das multinacionais (BRASILEIRO; ANDRADE, 2008). São lógicas diferentes de trabalho, que exige competências e formações distintas de atuação. O turismo de massa apresenta-se, portanto, como o modelo do turismo moderno, o ocidental, privando os autóctones do trabalho decente, do poder de participação e de decisões coletivas sobre a atividade turística no lugar.

Este modelo conduz à saturação do turismo, em consequência do esgotamento dos espaços naturais, da consciência ambiental, da exploração sem limites das culturas dos lugares, da padronização da oferta turística, dentre outros fatores. Como efeito, assiste-se a um declínio na demanda turística nesses destinos e, por consequência, uma fuga dos investimentos privados. Como analisa Zaoual (2008, p.3) “a procura da rentabilidade máxima destrói, em longo prazo, as bases dessa mesma rentabilidade". A uniformidade dos destinos e a especialização, distanciadas das verdadeiras vivências das pessoas do lugar, também são elementos favoráveis para o declínio do turismo de massa e, simultaneamente, para outro pensar nas formas de fazer turismo. Este agora mais voltado para o homem do que ao capital (CORIOLANO; SILVA, 2005).

É na diversidade, no valor do local, que estão as bases para pensar o turismo contemporâneo, principalmente nos lugares que não viveram o processo de turistificação da modernidade. 
Como afirma Zaoual (2008, p. 4), "os turistas querem ser atores, responsáveis e solidários em seus intercâmbios com outros mundos". Desde esta perspectiva, as vivências, tanto dos turistas como dos autóctones, são reais, verdadeiras, ao contrário das montagens elaboradas, dos simulacros criados pelo turismo de massa. As crenças, as motivações e as práticas dos atores da atividade turística, sejam eles autóctones ou turistas, são relações de sentidos múltiplos, diversos e concretizados na unicidade do lugar turístico.

Para tanto, esta perspectiva ainda necessita de mudanças no olhar, nos comportamentos, nos valores dos turistas e autóctones. As representações simbólicas construídas sobre o turismo, tanto dos turistas como dos autóctones, são elaboradas em base ao turismo de massa. Repensá-las é ressignificar o sentido atribuído aos turistas, não mais como sinônimo de lucro, emprego e renda, mas como pessoas que viajam e buscam vivências diferentes do seu cotidiano. Quanto aos autóctones, que são considerados os exóticos, ou, simplesmente, os que não necessitam ser vistos pelos turistas, possuem história, memórias, cotidiano e vivências múltiplas naqueles lugares turísticos. Os lugares turísticos, que para alguns turistas, tratam-se apenas de mais um destino a ser visitado, são, na realidade, o mundo, o cotidiano, o lugar de viver dos autóctones. Turistas e autóctones são realidades entrelaçadas e os destinos turísticos, mais que destinos, são mundos que se comunicam, diversidades que dialogam entre si.

Dentro de um mosaico de culturas proporcionado pela atividade turística, a trajetória histórica, cultural e ambiental do lugar, mais que produto turístico, é uma relação de intercâmbio de natureza simbólica. É a comunicação que enaltece 
no turista o vínculo com o lugar e produz uma identificação com o cotidiano nele vivido. Neste entendimento, são as potencialidades humanas, sejam elas dos autóctones ou dos turistas, que são valorizadas (PABLOS; MEDINA, 2004). Se o importante para o turista é estar em movimento, vir de fora, chegar ao lugar e viver essa natureza simbólica do visitado, para os autóctones é o estar dentro, é o estar no seu cotidiano, entrecruzando com outros mundos. É neste jogo complexo que se traduz o sentido do lugar turístico. Mais que cifras de uma economia, os lugares turísticos são pessoas, culturas e mundos que se movem.

Analisando a partir de outra ótica, o turismo não autoriza ao turista, nem aos planejadores e produtores desta atividade, o direito de manifestar suas vivências de lazer, suas políticas e investimentos, por meio do comprometimento da qualidade de vida do lugar vivido pelos autóctones. A falta de formação profissional, por exemplo, não justifica o subemprego na atividade turística. O desafio do turismo é, portanto, promover a qualidade de vida dos autóctones e vivências reais para os turistas. Uma via nesta perspectiva pode relacionar-se ao trabalho digno para os autóctones, por meio da organização de empresas de pequena escala. As ações afirmativas, neste sentido, convergem também para que haja as facilidades ao crédito, às tecnologias e à educação.

A educação aqui merece destaque. Não apenas de forma instrumental, limitada aos cursos de capacitação para o trabalho numa determinada função da atividade turística, principalmente no período da alta estação. O sentido de educação aqui empregado está associado aos valores do ser humano, que relaciona saberes, formas de pensar, sentir e agir do lugar, 
situado num contexto regional, nacional e mundial. Educação é formação. Mas como nos adverte Morin (2001a, p. 11), "a formação tem o defeito de ignorar que a missão do didatismo consiste em estimular o autodidatismo, despertando, suscitando, favorecendo a autonomia do espírito".

A educação está assim associada à autonomia, às liberdades humanas, à sustentabilidade, não só ambiental, cultural, social, mas à sustentabilidade do próprio ser. Não é aqui pensada a educação para os autóctones, mas educação com os autóctones, seja esta impulsionada por eles próprios, pelos planejadores turísticos, pelos empresários, pela academia ou quem quer que seja. A educação é a interculturalidade de saberes, sem hierarquização, sem aniquilação das significações simbólicas do contexto do lugar. É no lugar que há a complementaridade, a partilhada de conhecimentos, que possibilita a construção de diálogos e de novos saberes.

Ainda nesta perspectiva, outra via se relaciona também em pensar um compartilhamento das vivências de lazer e do lúdico entre os autóctones e turistas, por meio das práticas físico-esportivas, das artes e das festas. A dicotomia entre lazer para os turistas e vivências lúdicas dos autóctones seria superada por vivências lúdicas do lugar, sem distinções nem qualificativos. Os turistas vivenciariam a cultura do lugar, o cotidiano, o lúdico dos autóctones, e estes estariam vivendo o seu real, sem modelos nem simulações. Simular é "fingir ter o que não se tem" (BAUDRILLARD, 2002, p. 12). Assim sendo, o turismo para os autóctones não estaria vinculado apenas ao emprego e renda, com simulacros da sua cultura, mas como parte do seu cotidiano e das vivências lúdicas do lugar. 
A superação do eurocentrismo, da racionalidade positivista, com as dualidades do saber tradicional/moderno, emocional/racional, ser humano/natureza, turista/autóctone conduz, portanto, à reconstrução de um novo pensar. Como afirma Morin (2001b, p. 27), "a ideia do mundo europeu e mais largamente ocidental era a de que toda razão, sabedoria e verdade estavam concentradas na civilização ocidental". A crise do paradigma ocidental ajuda a entender melhor que cada lugar possui seus valores, encantos e desencantos. E a educação tem muito a dizer sobre o dar e o receber no turismo. Sobre a formação e o desenvolvimento dos valores humanos. Pensar em desenvolvimento e turismo, desde esta perspectiva, é pensar em uma reforma do pensamento humano (MORIN, 2001). É pensar, como afirma Morin, das partes ao todo e do todo a nós. Nós, turistas ou autóctones, dependendo de como estejamos situados no lugar.

\section{Considerações Finais}

Os avanços científicos, econômicos e tecnológicos da modernidade não foram suficientes para diminuir as misérias humanas, as dores causadas pelas guerras, nem a ganância pelo poder. A crise da modernidade conduz a novos valores e pensares, que colocam em questionamento o progresso e o crescimento econômico como fim último das sociedades. $\mathrm{O}$ aniquilamento dos conhecimentos locais - em detrimento dos saberes universais eurocêntricos -, a desvalorização dos modos de vida não europeus e as desigualdades geradas por este paradigma são repensados a partir de novos olhares sobre o desenvolvimento, como do desenvolvimento sustentável, das liberdades humana e dos sítios simbólicos de pertencimento. 
Estes novos paradigmas do desenvolvimento são, em realidade, a busca do resgate do humano. A valorização e o aproveitamento dos recursos e do saber-fazer das pessoas de cada lugar têm sua origem nos sucessivos fracassos de apostar em um crescimento ilimitado, de dominação da natureza pelo ser humano e de desvalorização da ética, seja ela associada ao social, econômico, cultural ou ao político. A qualidade de vida das pessoas toma centralidade nas discussóes sobre desenvolvimento.

O turismo, desde esta perspectiva de desenvolvimento, apresenta-se como uma possibilidade para a tomada de consciência, dos turistas e autóctones, como agentes sociais. Os saberes, formas de pensar e sentir, modos de fazer que, durante séculos de dominação ocidental, foram desconsiderados e desprezados, sinônimos de atraso sociocultural e econômico, são revalorizados por um novo modo de fazer e pensar o turismo. Neste contexto, a educação tem papel preponderante ao apreender que o desenvolvimento e o turismo têm por objetivo o desenvolvimento humano, ao mesmo tempo em que é uma ferramenta da população num processo de transformação social.

O desafio atual está na ressignificação, em um novo pensar sobre o desenvolvimento, o lugar e o turismo. Novos modelos de desenvolvimento serão adotados e os aspectos culturais, como forma de ser, sentir e de viver de um povo no mundo, serão um dos eixos do desenvolvimento, pensado para o ser humano, seja este um turista ou autóctone. O turismo, desde este paradigma é, portanto, uma atividade estimuladora de experiências e vivências das capacidades humanas. 


\section{Referências}

ANDERSON, P. Balanço do Neoliberalismo. In: SADER, Emir; GENTILI, Pablo (org.): Pós-neoliberalismo: as políticas sociais e o Estado Democrático. Rio de Janeiro: Editora Paz e Terra, 2008.

BAUDRILLARD, J. Cultura y simulacro. Barcelona:

Editorial Kairós, 2002.

BRASILEIRO, M. D. S. El deporte y el turismo de litoral: entre los cambios sociales. Granada/Espanha: Editora Universidad de Granada, 2007.

BRASILEIRO, M. D. S.; ANDRADE, L. M. B. O local e o global na atividade turística: um desafio para as comunidades de pescadores do litoral nordestino/Brasil. IN: OLIVEIRA, H. L.; SEIDEL, R. H. (orgs.). Póscolonialismo e globalização: culturas e desenvolvimento em questão. Feira de Santana: Editora Universidade Estadual de Feira de Santana, 2008.

CORIOLANO, L. N.; SILVA, S. C. B. Turismo e geografia: abordagens críticas. Fortaleza: Editora UECE, 2005.

DUPAS, G. O mito do progresso. São Paulo: Editora UNESP, 2006.

FURTADO, C. El desarrollo como proceso endógeno. Cultura e desenvolvimento em época de crise. Rio de Janeiro: Editora Paz e Terra, 1984. 
PABLOS, J. C. de; MEDINA, J. C. Las lógicas del turismo: del consumo a la construcción de la sociedad. IN: BLANQUER, D. Turismo cultural y urbano. Valencia (España), Tirant lo Blanch, 2004.

MORIN, E. La mente bien ordenada. Barcelona: Editorial Seix Barral, 2001a.

MORIN, E. Saberes globais e saberes locais. Rio de Janeiro: Garamond, 2001.

RIVERO, O. O mito do desenvolvimento: os países inviáveis no século XXI. Petrópolis (RJ): Vozes, 2002.

SACHS, I. Desenvolvimento includente, sustentável, sustentado. Rio de Janeiro: Garamond, 2008.

SEN, A. Desenvolvimento com liberdade. São Paulo: Companhia das Letras, 2000.

SOUZA, J. Europeização e Naturalização da Desigualdade: Em busca da gramática social da desigualdade brasileira. IN: I Seminário Internacional Regional de Estudos Interdisciplinares: Condição Humana e Modernidade no Cone Sul da América Latina, Programa de Doutorado Interdisciplinar em Ciências Humanas. Capítulo VIII da série.

VEIGA, J. E. da. Do global ao local. Campinas, Armazém do Ipê (Autores Associados), 2005.

ZAOUAL, H. Globalização e diversidade cultural. São Paulo: Cortez, 2003. 
98

ZAOUAL, H. Do turismo de massa ao turismo situado: quais as transições? Caderno Virtual de Turismo. Rio de janeiro, v. 8, n 2, p. 1-14, 2008.

ZAOUAL, H. O homo situs e sua perspectiva paradigmática. OIKOS. Rio de Janeiro, v. 9, nº 1, p. 13-39, 2010. 